\title{
Consumer Preference of Products for the Prevention and Treatment of Stretch Marks: Systematic Product Search
}

Pengyi Zhu*, BS; Andrew Fung", BSN, RN; Benjamin K P Woo*, MD

Olive View-University of California Los Angeles Medical Center, Sylmar, CA, United States

*all authors contributed equally

Corresponding Author:

Pengyi Zhu, BS

Olive View-University of California Los Angeles Medical Center

14445 Olive View Drive, Cottage H1

Sylmar, CA, 91342

United States

Phone: 16268171089

Email: sharonpzhu2@gmail.com

\begin{abstract}
Background: Striae distensae, or stretch marks, are a common and distressing condition affecting females two-and-a-half times more frequently than males. Despite the numerous products available for stretch mark prevention and treatment, there have been few studies that consider consumer product preference.

Objective: The aim of this study was to determine which products were preferred by consumers for the prevention and treatment of stretch marks based on product vehicle and product ingredients.

Methods: In January 2020, a search was conducted on internet retailer Amazon for products related to stretch marks. The top products were identified as those with 100 reviews or greater and a rating of 4 or higher. The products were classified as either stretch mark-specific or non stretch mark-specific. Price, rating, type of vehicle, and specific ingredients of both product groups were compared. Vehicle-type and ingredients in both product groups were compared with two-tailed two-sample proportion tests to determine if certain vehicles or ingredients were more likely to be found in stretch mark-specific products. $P<.05$ indicated statistical significance.

Results: Out of over 10,000 products, 184 were selected as the top products according to the review and rating criteria of which $117(63.6 \%)$ were stretch mark-specific and $67(36.4 \%)$ were non stretch mark-specific. Oil was the most common vehicle $(131 / 184,71.2 \%)$ while vitamin $\mathrm{E}$ was the most common ingredient $(58 / 184,31.5 \%)$. Oil, as a vehicle, was more likely to be found in stretch mark-specific products than in non stretch mark-specific products $(P=.001)$. Olive oil $(P=.02)$ and cocoa butter $(P=.08)$, Centella asiatica $(P=.01)$, and shea butter $(P=.003)$ were the ingredients more likely to be found in stretch mark-specific products than in non stretch mark-specific products.

Conclusions: This study demonstrated that there are many products available for the prevention and treatment of stretch marks and identified specific ingredients in the products preferred by customers. There are few studies investigating the effectiveness of the major ingredients in the stretch mark products that are preferred by consumers. Future studies can focus on the effectiveness of the ingredients found in the products that are preferred by consumers.
\end{abstract}

(JMIR Dermatol 2020;3(1):e18295) doi: 10.2196/18295

\section{KEYWORDS}

Amazon; consumer preference; stretch mark; striae distensae; striae gravidarum

\section{Introduction}

Striae distensae, more commonly known as stretch marks, are a common and disfiguring dermatological condition in which the layer of dermis becomes scarred. Striae distensae occur two-and-a-half times more frequently in females than in males
[1]. Striae distensae are more likely to develop during pregnancy (striae gravidarum), with obesity, with Cushing syndrome, during adolescence, with steroidal drug use, and after surgery [2].

The pathogenesis of striae distensae is multifactorial. Striae distensae are typically associated with rapid weight gain (such 
as in pregnancy) and rapid growth (such as in adolescence) as a result of tissue stretching [3]. Striae distensae are more common on the abdomen, breast, thigh, and buttocks $[1,4]$. Striae distensae caused by mechanical stress have been found to exhibit altered extracellular matrix components, primarily fibronectin, fibrillin, elastin, and collagen [5], through potential mechanisms such as low expression of genes for collagen and fibronectin, reduced fibroblast function, and disorganized fibrils or elastic fiber networks [3-5]. Studies of hormonal changes occurring in pregnancy, during steroid use, and in Cushing syndrome contribute to the understanding of the development of striae distensae; increased steroid levels cause increased protein catabolism and decreased production of collagen by fibroblasts resulting in less elastic fibers in the matrix of the dermis $[1,6]$.

Because of the distress caused by the disfiguring nature of stretch marks, studies have attempted to find methods to prevent and treat stretch marks [7]. Different topical agents have been used to target processes that lead to the development of stretch marks. Trofolastin, a product which contains Centella asiatica was found to stimulate fibroblasts and counteract the glucocorticoid effect [8]. Oils and cocoa butter assist with maintaining skin hydration, which influences the expression of cytokines and growth factors via occlusive mechanisms [5,9]. Tretinoin (a derivative of vitamin A) has been found to stimulate fibroblasts to increase collagen I production in tissue while ascorbic acid (vitamin C) has also been found to increases collagen production [5]. Despite the numerous topical therapies available, therapy efficacy has not been well studied.

Because of the lack of evidence regarding the effectiveness of prevention or treatment of stretch marks, individuals look to other sources when determining which products to purchase. In this study, we assess which products are available to consumers, which are popular among consumers, and factors determining which products are used for stretch marks.

\section{Methods}

A search was performed in January 2020 on United States internet retailer Amazon to identify the top products used for stretch marks. The searches performed were (1)"stretch mark" in All Departments: Beauty \& Personal Care, (2)"stretch mark cream" in All Departments, and (3) "stretch mark" in Beauty $\&$ Personal Care: Skin Care: Maternity. Products were included based on average customer rating (4 stars and higher out of a possible 5 stars) and number of customer reviews (100 reviews and greater). Product titles, product descriptions, customer question and answer sections, and customer review sections were reviewed for the phrase "stretch mark." Products were excluded if they were nontopical products such as masks, massage balls, massage cups, or socks; product sets with more than one type of item; or if there was no mention of "stretch mark" in the title, product description, customer question and answer section, or customer review section. The product listing with the highest number of reviews was included if the product had multiple listings for different quantities and sizes. Median rating, average rating, average number of reviews, vehicle-type, ingredient list, and median price per ounce or fluid ounce were determined for the overall sample of products. Because of the large variety of ingredients, only ingredients that had been investigated in previous studies for effectiveness in treating stretch marks were included in the analysis $[3,5,10,11]$.

Products were divided into two groups - stretch mark-specific products were those that included "stretch mark" in the product title, product description, or both and non stretch mark-specific products were those that included "stretch mark" in the customer question and answer section or the customer review section. To determine if a specific vehicle-type or specific ingredient was more likely to be found in a stretch mark-specific product, two-tailed two-sample proportion tests were used. $P<.05$ indicated statistical significance.

\section{Results}

Out of over 10,000 products on the United States internet retailer Amazon, 184 products met the required criteria. This group of products had a median consumer rating of 4.5 and a median of 409 reviews per product (range 103-10,573; total 183,366). The median price per ounce or per fluid ounce was $\$ 3.19$ (range $\$ 0.17$ - \$48; products that did not provide volume or weight information were not included: silicone sheet products, Crocodile acne scar removal cream, and Aliver TCM scar and acne mark removal gel ointment).

Products were categorized by vehicle-type. Out of 184 products, $131(71.2 \%)$ were oils, $21(11.4 \%)$ were creams, 9 (4.9\%) were butters, $9(4.9 \%)$ were gels, $5(2.7 \%)$ were silicone sheets, 3 $(1.6 \%)$ were lotions, $2(1.1 \%)$ were scrubs, and the remaining $4(2.2 \%)$ were categorized as other (balm, salve, ointment, and stick).

Of all 184 products, there were 117 (63.6\%) stretch mark-specific and 67 (36.4\%) non stretch mark-specific. Of the stretch mark-specific products, "stretch mark" was mentioned in the product title $(6 / 117,5.1 \%)$, product description $(75 / 117,64.1 \%)$, or both $(36 / 117,30.8 \%)$. "Stretch mark" was mentioned in the customer question and answer section (84/184, $45.7 \%$ ) and customer review section (138/184, 75.0\%). Customers mentioned "stretch mark" in relation to pregnancy or postpartum use in $70.1 \%$ of products (129/184). The top 10 most reviewed products are listed in Table 1 . The top 10 most reviewed stretch mark-specific products are listed in Table 2.

Of the 117 stretch mark-specific products, $76(65.0 \%)$ were oils, $17(14.5 \%)$ were creams, $8(6.8 \%)$ were butters, $6(5.1 \%)$ were gels, $3(2.6 \%)$ were silicone sheets, $3(2.6 \%)$ were lotions, $2(1.7 \%)$ were scrubs, $1(0.9 \%)$ was a balm, and $1(0.9 \%)$ was a salve. Of the 67 non stretch mark-specific products, 55 $(82.0 \%)$ were oils, $4(6 \%)$ were creams, $1(1.5 \%)$ was a butter, $3(4.5 \%)$ were gels, $2(3 \%)$ were silicone sheets, $1(1.5 \%)$ was an ointment, and $1(1.5 \%)$ was a stick. Oil as a vehicle was more likely to be found in the stretch mark-specific product group than in the non stretch mark-specific product group $(P=.001)$.

Of all 184 products, $7(3.8 \%)$ contained allantoin, $11(6 \%)$ contained aloe, $10(5.4 \%)$ contained C. asiatica, $20(10.9 \%)$ contained cocoa butter, 9 (4.9\%) contained collagen, 4 (2.2\%) contained hyaluronic acid, $23(12.5 \%)$ contained shea butter, 3 (1.6\%) contained vitamin A, $7(3.8 \%)$ contained vitamin C, and 
$58(31.5 \%)$ contained vitamin E. Out of the 117 stretch mark-specific products, 5 contained allantoin (4.3\%), 9 contained aloe $(7.7 \%), 10(8.5 \%)$ contained C. asiatica, 18 $(15.4 \%)$ contained cocoa butter, $7(6 \%)$ contained collagen, 4 (3.4\%) contained hyaluronic acid, $21(17.9 \%)$ contained shea butter, $2(1.6 \%)$ contained vitamin A, $6(5.1 \%)$ contained vitamin C, and $40(34.2 \%)$ contained vitamin E. Out of the 67 non stretch mark-specific products, $2(3 \%)$ contained allantoin, $2(3 \%)$ contained aloe, $0(0 \%)$ contained C. asiatica, $2(3 \%)$ contained cocoa butter, $0(0 \%)$ contained hyaluronic acid, 2 (3\%) contained shea butter, $1(1.5 \%)$ contained vitamin A, 1 (1.5\%) contained vitamin C, and $18(26.9 \%)$ contained vitamin E. Three ingredients were more likely to be found in stretch mark-specific products-cocoa butter $(P=.08), C$. asiatica $(P=.01)$, and shea butter $(P=.003)$.
Specific types of oil as ingredients were also investigated [5]. While there were a variety of oils present in the products, almond oil, coconut oil, and olive oil have been found to be present frequently in other literature and were the focus of this analysis. Of all 184 products, $40(21.7 \%)$ contained almond oil, $33(17.9 \%)$ contained coconut oil, and $18(9.8 \%)$ contained olive oil with remaining products containing other oils or no oils. Of the 117 stretch mark-specific products, 22 (18.8\%) contained almond oil, $22(18.8 \%)$ contained coconut oil, and $16(13.7 \%)$ contained olive oil. Of the 67 non stretch mark-specific products, 18 (26.9\%) contained almond oil, 11 (16.4\%) contained coconut oil, and $2(3 \%)$ contained olive oil. Olive oil was more likely to be found in stretch mark-specific products $(P=.02)$.

Table 1. Top 10 most reviewed products.

\begin{tabular}{lllll}
\hline & Manufacturer name & Product name & Number of reviews & Mean rating (out of 5) \\
\hline 1 & Pura D'or & Organic Jojoba Oil & 10,573 & 4.5 \\
2 & Bio-Oil & Skincare Oil & 9732 & 4.4 \\
3 & Sky Organics & Organic Castor Oil & 7164 & 4.5 \\
4 & Now Solutions & Sweet Almond Oil & 6861 & 4.7 \\
5 & M3 Naturals & Anti Cellulite Massage Oil & 5048 & 4.6 \\
6 & First Botany Cosmeceuticals & Arabica Coffee Scrub & 4839 & 4.0 \\
7 & Burt's Bees Mama Bee & Belly Butter & 4660 & 4.4 \\
8 & Pura D'or & Organic Rosehip Seed Oil & 4332 & 4.6 \\
9 & Ancient Greek Remedy & Ancient Greek Remedy Oil & 4249 & 4.6 \\
10 & Honeyskin & Ultimate Face \& Body Cream & 3359 & 4.3 \\
\hline
\end{tabular}

Table 2. Top 10 most reviewed stretch mark-specific products.

\begin{tabular}{lllll}
\hline & Manufacturer name & Product name & Number of reviews & Mean rating (out of 5) \\
\hline 1 & Bio-Oil & Skincare Oil & 9732 & 4.4 \\
2 & Sky Organics & Organic Castor Oil & 7164 & 4.5 \\
3 & M3 Naturals & Anti Cellulite Massage Oil & 5048 & 4.6 \\
4 & First Botany Cosmeceuticals & Arabica Coffee Scrub & 4839 & 4.0 \\
5 & Burt's Bees Mama Bee & Belly Butter & 4660 & 4.4 \\
6 & Ancient Greek Remedy & Ancient Greek Remedy Oil & 4249 & 4.6 \\
7 & Honeyskin & Ultimate Face \& Body Cream & 3359 & 4.3 \\
8 & Coco \& Co. & The Purest Coconut Virgin Oil & 2858 & 4.7 \\
9 & Palmer's Cocoa Butter Formula & Massage Lotion For Stretch Marks & 2654 & 4.3 \\
10 & Majestic Pure Cosmeceuticals & Rosehip Oil & 2647 & 4.4 \\
\hline
\end{tabular}

\section{Discussion}

\section{Principal Findings}

Over 10,000 products for stretch marks were found on Amazon, indicating the broad and diverse array of products ranging from topical to physical products (such as masks and socks) that are available for consumers. In this study, only topical products were assessed to limit the discussion of effectiveness to certain ingredients (those previously studied), but even with past studies, there has been no consensus regarding the effectiveness of topical products. As such, consumers rely upon information and suggestions posted by consumers on internet retail websites such as Amazon.

There is a disparity between the characteristics of products that are intended for use on stretch marks and the characteristics of products that are used on stretch marks based on customer 
reviews. Out of all 184 products, $63.6 \%$ (117) were intended for use on stretch marks, while $36.4 \%$ (67) were not intended for stretch marks but were used nonetheless based on customer reviews or customer questions and answers. This indicated that customers may be purchasing ineffective products by relying upon the opinions of others; $45.7 \%$ (84/184) of products had a question regarding stretch marks in the question and answer section, 75\% (138/184) of products mentioned "stretch marks" in the reviews, and $70.1 \%(129 / 184)$ of products mentioned "stretch marks" related to pregnancy. The number of products that had a combination of "stretch marks" being mentioned in either question and answer section, reviews, and in relation to pregnancy was not differentiated. Previous studies have also shown that patients seek advice from friends, product advertisements, and the internet, particularly in the early stages of pregnancy [12].

The majority of the top products that were found when searching "stretch mark" were oils-131 (71.2\%) of the top 184 products. Stretch mark-specific products were more likely to be oils than non stretch mark-specific products as demonstrated by the two-sample proportion test. Oils help retain moisture in the skin, but oils rich in linoleic acid and polyunsaturated fatty acids, such as olive oil, have also been found to reduce the formation of scars by reducing pro-inflammatory mediators (tumor necrosis factor alpha and peroxisome proliferator-activated receptors) which assists with wound healing [13]. Other studies, however, have produced conflicting findings. Studies have found that olive oil does not significantly reduce the incidence of striae gravidarum $[14,15]$, while a study on almond oil demonstrated its possible effectiveness through its role in decreasing the progression of striae gravidarum by preventing itchiness when massaged into the skin [16,17]. In our study, specific oils that were found to be ingredients in the top products included, but were not limited to, apricot oil, argan oil, avocado oil, canola oil, castor oil, emu oil, grapefruit oil, jojoba oil, safflower oil, and sunflower oil. Recent studies have focused on almond oil, coconut oil, and olive oil [5]. This raises the question if enough studies on oils have been conducted, particularly because there have been contradictory findings on the effectiveness reported by studies. The amount of available studies on oils does not reflect the popularity of oils among consumers for stretch mark prevention and treatment. Furthermore, several studies suggest the therapeutic effect of massage in relation with oil for the prevention of stretch marks $[1,16]$. This further indicates that there is not enough understanding concerning oils and their use for stretch marks.

Out of the major ingredients assessed in this study, vitamin E was the most commonly used ingredient in both stretch mark-specific $(40 / 117,34.2 \%)$ and non stretch mark-specific products $(18 / 67,26.9 \%)$. A prior study showed that olive oils were rich in vitamin E, yet the findings did not suggest that olive oils were effective in the prevention of striae gravidarum [14]. Almond oil is also rich in vitamin E and vitamin D, yet a previous study also did not demonstrate the effectiveness of almond oil on its own for striae gravidarum [16]. Thus, future studies may wish to continue to assess which ingredients are effective for stretch mark prevention.
Creams comprised $11.4 \%$ (21/184) of the top products; creams comprised $14.5 \%(17 / 117)$ of stretch mark-specific products and $6 \%(4 / 67)$ of non stretch mark-specific products. Creams have been found to be the type of product most used by pregnant patients for prevention of stretch marks [4]. Previous studies stated an incidence of $50 \%$ to $90 \%$ for the development of striae gravidarum [18], indicating a large population of individuals who may seek out striae gravidarum products. Another cross-sectional study demonstrated high use of Bio-Oil by patients for the prevention of striae gravidarum [12], which is consistent with our finding that Bio-Oil was the most reviewed stretch mark-specific product. Product effectiveness and safety are of concern, especially during pregnancy. Furthermore, cream treatments such as Alphastria (containing hyaluronic acid, allantoin, vitamin $\mathrm{A}$, and vitamin E) and Verum (containing vitamin $\mathrm{E}$ and hyaluronic acid) were not found to be in the top 10 product list, nor were their ingredients found in the top 10 products, despite having been studied and shown to have possible benefits in stretch mark prevention [1,5]. This demonstrates a discrepancy between the products that are being studied and the products that consumers are actually using, suggesting the need for consumers to be educated.

We focused our study on ingredients that had been mentioned in previous studies [3,5,10,11]. Cocoa butter, $C$. asiatica, and shea butter were more likely to be found as ingredients in products intended for stretch marks. In a previous study, the findings regarding the efficacy of cocoa butter for striae gravidarum prevention did not support its use despite cocoa butter's moisturizing effects $[6,19]$. Trofolastin (containing $C$. asiatica, vitamin E, and collagen-elastin hydrolysates) was also studied for the prevention of striae gravidarum and demonstrated significant prevention of stretch marks during pregnancy likely due to fibroblast stimulation and glucocorticoid antagonism $[1,5,8]$. Though shea butter is known to reduce fibroblasts [3], and there have been studies on whether shea butter is or is not effective for stretch marks, it is more likely to be found in products intended for stretch marks. Other products may have studies indicating their efficacy but may not be specifically indicated for the prevention of stretch marks. Aloe vera has been studied for its effectiveness in decreasing itchiness, and thus, the progression of stretch marks [17]. Tretinoin (or other vitamin A derivatives) has demonstrated some efficacy in preventing stretch marks, but is not found primarily in stretch mark-specific products [6]. Furthermore, tretinoin as well as ascorbic acid and hyaluronic acid are ingredients known to promote production of collagen [5]. Hyaluronic acid increases the skin's ability to resist tension, likely due to a mechanism of increased collagen production, yet minimal evidence has been found for its effectiveness $[5,6]$. These discrepancies show the gaps between what is effective and what is communicated to consumers about a product's effectiveness. Further studies should focus the ingredients being used the most by consumers in order to understand the ingredient's mechanism and effectiveness in stretch mark prevention.

\section{Limitations}

One limitation was the size of the overall study. There were over 10,000 products listed for "stretch mark" when searching the online retailer Amazon; however, we only included the top 
products by screening ratings and number of reviews. As such, we did not assess products with lower ratings and less reviews which would have been able to give us a broader idea of which products were being used by consumers for stretch marks. We also excluded products that did not mention "stretch mark" in the title, description, question and answer section, or review section, thus we did not assess what other types of ingredients were potentially being used for stretch marks. Another limitation of our study was that while we considered products that mentioned "stretch mark" in the product review, we did not assess whether the review was positive or negative. Future studies could potentially compare positive and negative consumer product reviews to understand the subjective effectiveness of products.

\section{Conclusions}

As demonstrated from our search on the internet retailer Amazon for products related to stretch marks, there are a plethora of products and ingredients for stretch marks; however, with few studies on the effectiveness of ingredients and products, consumers may rely upon consumer reviews when selecting products. More studies are needed to determine effectiveness and safety of ingredients, particularly with respect to pregnant women.

\section{Conflicts of Interest}

None declared.

\section{References}

1. Elsaie ML, Baumann LS, Elsaaiee LT. Striae distensae (stretch marks) and different modalities of therapy: an update. Dermatol Surg 2009 Apr;35(4):563-573. [doi: 10.1111/j.1524-4725.2009.01094.x] [Medline: 19400881]

2. Tsuji T, Sawabe M. Elastic fibers in striae distensae. J Cutan Pathol 1988 Aug;15(4):215-222. [doi: 10.1111/j.1600-0560.1988.tb00547.x] [Medline: 3183137]

3. Ud-Din S, McGeorge D, Bayat A. Topical management of striae distensae (stretch marks): prevention and therapy of striae rubrae and albae. J Eur Acad Dermatol Venereol 2016 Feb 20;30(2):211-222 [FREE Full text] [doi: 10.1111/jdv.13223] [Medline: 26486318$]$

4. Al-Himdani S, Ud-Din S, Gilmore S, Bayat A. Striae distensae: a comprehensive review and evidence-based evaluation of prophylaxis and treatment. Br J Dermatol 2014 Mar 12;170(3):527-547. [doi: 10.1111/bjd.12681] [Medline: 24125059]

5. Lokhande A, Mysore V. Striae distensae treatment review and update. Indian Dermatol Online J 2019;10(4):380. [doi: 10.4103/idoj.idoj 336 18]

6. Korgavkar K, Wang F. Stretch marks during pregnancy: a review of topical prevention. Br J Dermatol 2015 Mar 08;172(3):606-615. [doi: 10.1111/bjd.13426] [Medline: 25255817]

7. Yamaguchi K, Suganuma N, Ohashi K. Prevention of striae gravidarum and quality of life among pregnant Japanese women. Midwifery 2014 Jun;30(6):595-599. [doi: 10.1016/j.midw.2013.07.011] [Medline: 23962637]

8. Mallol J, Belda M, Costa D, Noval A, Sola M. Prophylaxis of striae gravidarum with a topical formulation. a double blind trial. Int J Cosmet Sci 1991 Feb;13(1):51-57. [doi: 10.1111/j.1467-2494.1991.tb00547.x]

9. Rawlings AV, Bielfeldt S, Lombard KJ. A review of the effects of moisturizers on the appearance of scars and striae. Int J Cosmet Sci 2012 Dec 21;34(6):519-524. [doi: 10.1111/j.1468-2494.2012.00751.x] [Medline: 22994859]

10. Ross NA, Ho D, Fisher J, Mamalis A, Heilman E, Saedi N, et al. Striae distensae: preventative and therapeutic modalities to improve aesthetic appearance. Dermatol Surg 2017 May;43(5):635-648. [doi: 10.1097/DSS.0000000000001079] [Medline: 28375972]

11. Hague A, Bayat A. Therapeutic targets in the management of striae distensae: A systematic review. J Am Acad Dermatol 2017 Sep;77(3):559-568.e18. [doi: 10.1016/j.jaad.2017.02.048] [Medline: 28551068]

12. Brennan M, Clarke M, Devane D. The use of anti stretch marks' products by women in pregnancy: a descriptive, cross-sectional survey. BMC Pregnancy Childbirth 2016 Sep 21;16(1):276 [FREE Full text] [doi: 10.1186/s12884-016-1075-9] [Medline: 27654661]

13. Bielfeldt S, Blaak J, Staib P, Simon I, Wohlfart R, Manger C, et al. Observer-blind randomized controlled study of a cosmetic blend of safflower, olive and other plant oils in the improvement of scar and striae appearance. Int J Cosmet Sci 2018 Feb 12;40(1):81-86. [doi: 10.1111/ics.12438] [Medline: 29094366]

14. Taavoni S, Soltanipour F, Haghani H, Ansarian H, Kheirkhah M. Effects of olive oil on striae gravidarum in the second trimester of pregnancy. Complement Ther Clin Pract 2011 Aug;17(3):167-169. [doi: 10.1016/j.ctcp.2010.10.003] [Medline: 21742284]

15. Soltanipoor F, Delaram M, Taavoni S, Haghani H. The effect of olive oil on prevention of striae gravidarum: a randomized controlled clinical trial. Complement Ther Med 2012 Oct;20(5):263-266. [doi: 10.1016/j.ctim.2012.05.001] [Medline: 22863639]

16. Timur Taşhan S, Kafkasli A. The effect of bitter almond oil and massaging on striae gravidarum in primiparaous women. J Clin Nurs 2012 Jun 22;21(11-12):1570-1576. [doi: 10.1111/j.1365-2702.2012.04087.x] [Medline: 22594386]

17. Hajhashemi M, Rafieian M, Rouhi Boroujeni HA, Miraj S, Memarian S, Keivani A, et al. The effect of Aloe vera gel and sweet almond oil on striae gravidarum in nulliparous women. J Matern Fetal Neonatal Med 2018 Jul 19;31(13):1703-1708. [doi: 10.1080/14767058.2017.1325865] [Medline: 28521546] 
18. Chang ALS, Agredano YZ, Kimball AB. Risk factors associated with striae gravidarum. J Am Acad Dermatol 2004 Dec;51(6):881-885. [doi: 10.1016/j.jaad.2004.05.030] [Medline: 15583577]

19. Osman H, Usta IM, Rubeiz N, Abu-Rustum R, Charara I, Nassar AH. Cocoa butter lotion for prevention of striae gravidarum: a double-blind, randomised and placebo-controlled trial. BJOG 2008 Aug;115(9):1138-1142 [FREE Full text] [doi: 10.1111/j.1471-0528.2008.01796.x] [Medline: 18715434]

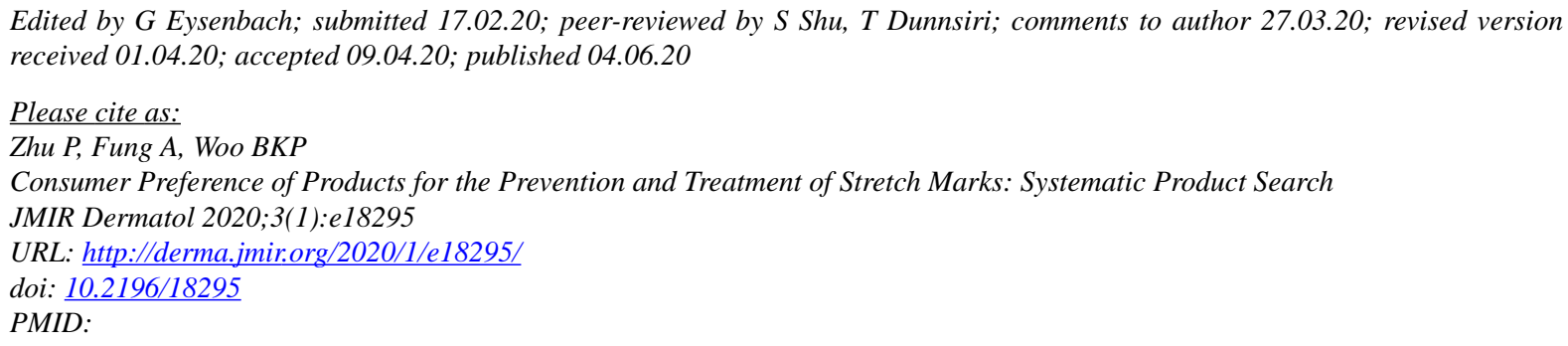

CPengyi Zhu, Andrew Fung, Benjamin K P Woo. Originally published in JMIR Dermatology (http://derma.jmir.org), 04.06.2020. This is an open-access article distributed under the terms of the Creative Commons Attribution License (https://creativecommons.org/licenses/by/4.0/), which permits unrestricted use, distribution, and reproduction in any medium, provided the original work, first published in JMIR Dermatology Research, is properly cited. The complete bibliographic information, a link to the original publication on http://derma.jmir.org, as well as this copyright and license information must be included. 